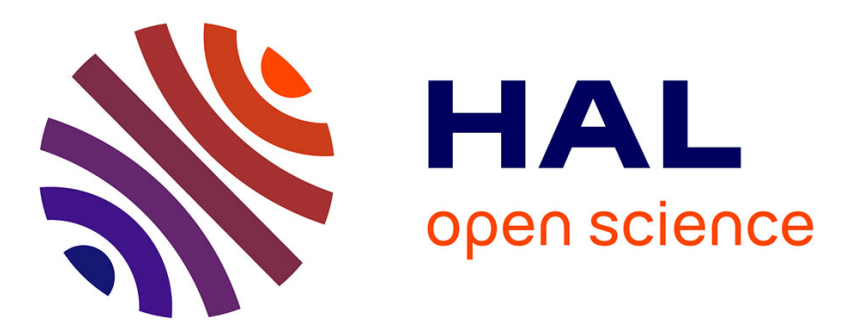

\title{
Facile immobilization of pyridine at gold, silver, and carbon surfaces. Generation of multi-strata versatile electrodes.
}

\author{
Viatcheslav Jouikov, Jacques Simonet
}

\section{- To cite this version:}

Viatcheslav Jouikov, Jacques Simonet. Facile immobilization of pyridine at gold, silver, and carbon surfaces. Generation of multi-strata versatile electrodes.. Electrochemistry Communications, 2015, 56, pp.20-23. 10.1016/j.elecom.2015.03.020 . hal-01151351

HAL Id: hal-01151351

https://hal-univ-rennes1.archives-ouvertes.fr/hal-01151351

Submitted on 18 Nov 2015

HAL is a multi-disciplinary open access archive for the deposit and dissemination of scientific research documents, whether they are published or not. The documents may come from teaching and research institutions in France or abroad, or from public or private research centers.
L'archive ouverte pluridisciplinaire HAL, est destinée au dépôt et à la diffusion de documents scientifiques de niveau recherche, publiés ou non, émanant des établissements d'enseignement et de recherche français ou étrangers, des laboratoires publics ou privés. 


\title{
Facile immobilization of pyridine at gold, silver, and carbon surfaces. Generation of multi-strata versatile electrodes.
}

\author{
Viatcheslav Jouikov ${ }^{\mathrm{a}^{*}}$ and Jacques Simonet ${ }^{\mathrm{b}^{*}}$ \\ a) CPM, UMR 6226, Université de Rennes 1, Campus de Beaulieu, 35042 Rennes Cedex, France \\ b) Laboratoire MaSCE, UMR 6226, Université de Rennes 1, Campus de Beaulieu, 35042 Rennes \\ Cedex, France.
}

\begin{abstract}
Electrochemical reduction of $4-\left(\omega\right.$-haloalkyl)pyridines $\left(\mathrm{Py}-\left(\mathrm{CH}_{2}\right)_{\mathrm{n}}-\mathrm{X}, \mathrm{X}=\mathrm{I}, \mathrm{Br}\right.$, and $\left.\mathrm{Cl}\right)$ in organic polar solvents leads to the efficient immobilization of pyridine at various solid electrodes (in particular at gold and different carbons). It is expected that the primarily immobilized pyridine layer (first stratum) is reactive towards the haloalkyl substrate in solution to afford-especially with iodides-multi-pyridinium layers readily electroactive in the course of electrolyses. Similar behaviour, though much slower, was observed for Py- $\left(\mathrm{CH}_{2}\right)_{\mathrm{n}^{-}}$ Br. These experimental evidences were applied to build different combined layers (e.g., reacting primary pyridine deposits-by simple dipping in the corresponding solution-with different electrophilic reagents like 1-iodoalkanes eventually labelled with ferrocene). This new modification process, supposedly extendable to many $\mathrm{N}$-aromatic systems, appears as a new mode of making functional multilayer or redox-active onium-type electrodes by cathodic activation of carbon-halogen bond scission.
\end{abstract}

Key words: Pyridine layer formation; Pyridine electrodes; Activation by pyridine; Pyridinium electrodes.

Corresponding authors: vjouikov@univ-rennes1.fr, jacques.simonet@univ-rennes1.fr

\section{Introduction}

The coverage of solid surfaces with functional organic layers conveying them specific properties remains a subject of high interest, especially in the field of catalysis. The electrochemical method provides a privileged way to modify solid conductors and to build new models of electrodes. In this aspect, grafting of organic moieties to carbon and gold electrode surfaces could be based on adsorption, on addition of organic radicals or on internal 
changes of these materials. Presently, this field is well documented principally concerning chemical modifications of carbons [1] with aryl-diazonium cations [2] as a facile source of aryl radicals formed at convenient potentials. At different carbon surfaces (glassy carbon, graphene), specific ways of modifications based on the cathodic charge of these materials have been developed [3]. In contrast, gold could appear as a less practical material for inducing surface modifications because the stability of adjuncts and the usable potential window ( $>-1.8 \mathrm{~V})$ are poorer; the examples of grafting at Au are also less documented [4].

Due to inherent restrictions of synthetic methods, grafting of ligands (or organic donors) is somewhat handicapped with respect to the large palette of available functions. We wish to enlarge this field by proposing a general method for decoration of carbons, silver, and gold with pyridine providing highly adjustable material surfaces. First of all, pyridine is not electroreducible in its neutral form [5], except at a lead cathode [6]. A recent work based on the electrocatalysis brought by nitrogen ligands was reported [7]. In the field of surface modification, pyridine immobilization could be indirectly achieved by use of a diazonium intermediate with a rigid phenylethynyl arm [8,9]. Our proposal concerns the electrochemical reactivity (in non-aqueous polar solvents in the presence of tetraalkylammonium salts $(\mathrm{TAAX})\}$ of electrophilic reagents from the family of $4-(\omega$-haloalkyl)pyridines, $p$-(X$\left.\mathrm{CH}_{2}\right)_{\mathrm{n}} \mathrm{C}_{5} \mathrm{H}_{5} \mathrm{~N}$. Surprisingly, these derivatives are quite readily reducible at gold, especially iodides, despite the fact that neither pyridine nor chloro and bromoalkanes show reduction waves at gold or glassy carbon at potentials $>-2 \mathrm{~V}$. We are probably dealing with the conjunction of two additional effects: catalysis by the electrode material and the intrinsic nucleophilic effect of pyridine nitrogen towards the primary carbon-halogen terminal bond.

The preliminary work presented here essentially focuses on the grafting of substrates of general formula $p-\left(\mathrm{X}-\mathrm{CH}_{2}\right)_{\mathrm{n}} \mathrm{C}_{5} \mathrm{H}_{5} \mathrm{~N},-(\mathbf{1}) \mathrm{X}=\mathrm{I}, \mathrm{n}=7$, (2) $\mathrm{X}=\mathrm{Br}, \mathrm{n}=8$, and (3) $\mathrm{X}=\mathrm{Cl}, \mathrm{n}=$ 7. The mechanism of formation of such layers, presumably involving radical transients and pyridinium salts - at least with iodides - and their reactivity and applications in the field of surface catalysis are discussed here for the first time.

\section{Experimental}

\subsection{Salts and solvents}

In this work, $0.1 \mathrm{M}$ solutions of tetra- $n$-butylammonium and tetramethylammonium tetrafluoroborates $\left(\mathrm{TBABF}_{4}\right.$ and $\left.\mathrm{TMABF}_{4}\right)$ in dimethylformamide (DMF) purchased from Merck (quality for syntheses) were used. It is worth mentioning that the procedures given hereafter do not require extremely dry solutions (water content $<1000 \mathrm{ppm}$ ) although, for 
excluding oxygen, all electrochemical experiments were performed under an inert atmosphere by bubbling of dry argon through the solution.

The reported potentials refer to aqueous $\mathrm{Ag} / \mathrm{AgCl}($ satur. $\mathrm{KCl}$ ) electrode. The electrochemical instrumentation has been previously described [4,5].

\subsection{Working electrodes}

All electrodes used in voltammetry had an apparent surface area of $0.8 \mathrm{~mm}^{2}$. Before use, gold, silver, and glassy carbon electrode surfaces were carefully polished with silicon carbide paper (Struers 500 and 1200) or with Norton polishing paper (type 02 and 03) and rinsed with water, then alcohol and at last with acetone. After recurrent scans or fixed potential electrolyses, electrodes were sonicated for two minutes. Finally, before analysis, the electrodes were dried with a hot air flow during about $30 \mathrm{~s}$. Coulometry measurements and electrolyses of alkyl halides reported in this work were carried out in three-electrode cells with a total catholyte volume of about $5 \mathrm{~mL}$. A fritted glass separated the two compartments.

\subsection{Organic materials}

Haloalkyl pyridines used in this work were synthesised from 4-methylpyridine (Aldrich) using methyl lithiation by the method adapted [5]. Primary alkyl iodides and reference electrophilic substrates were purchased from Aldrich and used without any additional purification.

\section{Results}

\subsection{Electrochemical behaviour of 4-(7-iodoheptyl)pyridine (1)}

As pictured in Figure 1 (A1), the reduction of $\mathbf{1}$ at GC electrodes shows a main irreversible cathodic step $\left(\mathrm{E}_{1 / 2}=-1.08 \mathrm{~V}\right)$ in the first scan; this peak progressively splits into two, I and II, probably reflecting a self-inhibition process. After several scans, there remains a sole sharp peak $\left(E_{p}=-1.09 \mathrm{~V}\right)$ while step II $\left(E_{p}=-1.21 \mathrm{~V}\right)$ totally vanished. It is expected that $\mathbf{1}$ is partly reduced into a transient alkyl radical capable to add to the carbon surface. Afterwards, this primarily immobilized pyridine layer may react with $\mathbf{1}$ in solution leading to pyridinium iodide (more electroactive than 1) to be immediately reduced. After several scans, the electrode-strongly inhibiting-is covered with a dense pyridine-containing layer whose structure can be envisioned as a poly-layer of alternating alkyl-pyridinium strata (Scheme 1; also, see a FTIR spectra of the GC- $\left(\mathrm{CH}_{2}\right)_{8} \mathrm{Py}$ surface obtained by use of $\mathbf{2}$ and reacted with $\mathrm{C}_{5} \mathrm{H}_{11} \mathrm{I}$, Figure 3B). In order to check this assertion, the carbon electrode was removed 
immediately after the first full scan, sonicated and rinsed with acetone, then dried and dipped into a solution of 1-iodoalkane for a few tens of seconds. The electrochemical response of this thus-prepared electrode in a DMF-TBABF 4 solution was identical to that in the primary solution which permitted grafting onto the initial carbon electrode. After a new rinsing, this electrode exhibited a single sharp peak $\left(E_{p}=-1.13 \mathrm{~V}\right.$ very close to that of step II), pictured in Figure 1 (A2), assigned to the reduction of a grafted heptyl-pyridinium monolayer. Integration of its current led to $\Gamma_{\left(\mathrm{CH}_{2}\right)_{7} \mathrm{Py}^{+}}=7 \times 10^{-10} \mathrm{~mol} \mathrm{~cm}{ }^{-2}$. This value is worth being compared to the sole peak I observed after several scans (assumed to be related to the formation of polypyridinium stacks) that globally afford a multilayer with significantly larger coverage level, $\Gamma$ $>3 \times 10^{-9} \mathrm{~mol} \mathrm{~cm}^{-2}$.

The reduction of $\mathbf{1}$ at a smooth gold electrode reveals a catalytic effect with a large shift of potentials towards less negative values compared to glassy carbon (Figure 1, B1). The main reduction step at $E_{1 / 2}=-0.87 \mathrm{~V}$ is followed by a secondary step $\left(E_{p}=-1.16 V\right)$ that overgrows the first one upon repetitive scans until total disappearance of both. It is proposed that the first step deals with the catalytic peak (cleavage of C-I bond at gold generating alkyl radicals) whereas the second one is assigned to reduction of pyridinium cations incorporated into the first layer as a result of the reaction with $\mathbf{1}$. Growth of the primarily attached layer causes the depression of catalysis (until step I almost totally vanishes). Dipping the modified electrode (after B1) in the solution of 6-iodohexylferrocene permits one (after ultrasonic rinsing) to obtain a very sharp signal assigned to immobilization of ferrocene via alkyl pyridinium transient. Actually, this reduction peak can be seen as catalytic reduction of iodoalkane due to its reaction with pyridine. Current integration leads to a surface concentration $\Gamma_{\mathrm{Py}-\mathrm{Fc}}=9 \times 10^{-}$ ${ }^{10} \mathrm{~mol} \mathrm{~cm} \mathrm{~cm}^{-2}$ assuming that pyridinium moieties are distributed in a monolayer. Moreover, the concentration of ferrocene was separately estimated through its oxidation (B4) giving $\Gamma_{\mathrm{Fc}}=3$ $\times 10^{-9} \mathrm{~mol} \mathrm{~cm}^{-2}$. This value looks a little higher than expected, but the exact location of immobilization of ferrocene (onto gold or onto pyridine) remains uncertain for the moment.

The use of silver cathodes permitted one to notice a catalytic effect already reported for alkyl iodides $[11,12]$. In the case of pyridines, immobilization was marked with a sharp peak $\left(\mathrm{E}_{\mathrm{p}}=-1.02 \mathrm{~V}\right)$ quite stable upon multiscan voltammetry. Globally, the feature is quite similar to that obtained at gold.

\subsection{Cathodic behaviour of bromo- and chloroalkyl pyridines}

Quite surprisingly, the reduction of these haloalkylpyridines at gold electrodes led to very similar results: as a matter of fact, $\mathbf{2}$ and $\mathbf{3}$ exhibit virtually identical two-step patterns with 
peaks at -0.78 and $-1.04 \mathrm{~V}$ (Figure $2 \mathrm{~A}$ and B). These two steps could simply be assigned to two successive one-electron transfers, the first one leading to a free alkyl radical readily grafted to the surface. This behaviour is rather classical at Pd or Au electrodes [13]. The absence of a sharp growing peak (as observed for iodide, §3.1) is attributed to slow, if any, formation of pyrinidium with $\mathbf{1}$ and $\mathbf{2}$. The modified electrode after several scans with Br-RPy affords an irreversible step II $\left(E_{p}=-1.05 \mathrm{~V}\right)$ that could be assigned to the reduction of pyridinium cations (Figure 2, A2). Anyhow, the deposit of pyridine onto GC (SEM of primary grafted surface shown in Figure 3A) and Au could be checked treating the produced surfaces with $0.1 \mathrm{~N} \mathrm{HCl}$ or $\mathrm{HClO}_{4}$ solutions: after rinsing and drying, FTIR spectra of these electrodes show the vibrations of pyridinium salts $\left(v_{\mathrm{N}-\mathrm{H}}\right.$ after treatment with $\mathrm{HCl}$, and $v_{\mathrm{N}-\mathrm{H}}$ and a large band of $\mathrm{ClO}_{4}{ }^{-}$anion when treated with $\mathrm{HClO}_{4}$ ) and a corresponding peak appears within the potential range of pyridinium reduction. Inhibition of produced surfaces by alkylpyridine deposits could also be evidenced by depression of Fc oxidation and by EIS experiments unravelling two time constants, the larger one supposedly related to octyl sublayer underlying the outer pyridyl layer (Figure 3).

\section{Conclusion}

Grafting of halo-alkylpyridines can be achieved at solid electrodes such as glassy carbon, gold and silver in a simple way by use of organic reagents that are quite easy to synthesize. Immobilized layers appear to be dense and stable (at least at gold and GC). Unexpectedly, an alkylpyridine layer grafted by use of the iodoalkyl precursor entails snowball reactions transforming pyridine centers into $\mathrm{N}$-( $\omega$-pyrid-4-yl)alkylpyridinium and leading to the formation of alkylpyridinium multi-strata coverages of the electrode surface; their reduction resets the interface to a simple (first grafted) layer of alkylpyridine. Reaction of such pyridine coverages with efficient electrophiles (e.g., alkyl iodides or activated bromides like propargyl or allyl bromides) opens a promising way for building new kinds of modified electrodes. Additionally, transient radicals issued from the cathodic scissions of pyridinium moieties can add onto the external layer of heterocylcles. The present method is obviously applicable to several redox-active, nitrogen-aromatic heterocycles. Finally, first attempts of grafting bipyridines using the methodology of this preliminary work were successful; such systems have a good promise for direct electrochemistry of proteins and metalloenzymes and for heterogeneous catalysis by transition-metal complexes. 


\section{References}

[1] R.L. McCreery, Chem. Rev. 108 (2008) 2646.

[2] D. Bélanger, J. Pinson, Chem. Soc. Rev. 40 (2011) 3995.

[3] V. Jouikov, J. Simonet, Electrochem. Commun., 45 (2014) 32.

[4] V. Jouikov, J. Simonet, Electrochem. Commun., 40 (2014) 58.

[5] J. F. Ambrose, L. L. Carpenter, R.F. Nelson, J. Electrochem. Soc., 122 (1975) 876.

[6] E. P. Hart, J. Chem. Soc. (1953) 3872.

[7] H. Khoshro, H. R. Zare, A. A. Jafari, A. Gorjii, Electrochem. Commun., 51 (2015) 63.

[8] W. Zhao, B. Tong, Y. Pan, J. Shen, J. Zhi, J. Shi and Y. Dong, Langmuir, (2009) 11796.

[9] B. Tong, H. Yang, W. Xiong, F. Xie, J. Shi, J. Zhi, W.K. Chan, Y. Dong, J. Phys. Chem. B, 117 (2013) 5338.

[10] M. Groarke, I.S. Gonçalves, W.A. Herrmann, F.E. Kühn, J. Organomet. Chem., 649 (2002) 108.

[11] V. Jouikov, N. Stephant, P. Poizot, J. Simonet, Electrochem. Commun., 51 (2015) 125.

[12] A. A. Isse, B. Giacomo, L. Falciola, M. Rossi, P. R. Mussini, A. Gennaro. J. Appl. Electrochem., 39 (2009) 2217.

[13] V. Jouikov, J. Simonet, ChemPlusChem., 78 (2013) 70.

\section{Figure captions}

\section{Figure 1}

Fixation of pyridine moieties onto GC and Au from 4-(7-iodoheptyl)pyridine $\left(2.5 \mathrm{mmol} \mathrm{L}^{-1}\right)$ in $\mathrm{DMF} / 0.1 \mathrm{M} \mathrm{TBABF}_{4}$.

(A) GC electrode. (1) Multi-scan voltammetry, scan rate $20 \mathrm{mV} \mathrm{s}^{-1}$. (2) Former electrode dipped in 1-iodopentane $\left(10^{-2} \mathrm{~mol} \mathrm{~L}^{-1}\right)$. Scan rate $50 \mathrm{mV} \mathrm{s}^{-1}$.

(B) Gold electrode. Scan rate $100 \mathrm{mV} \mathrm{s}^{-1}$. (1) Multi-scan voltammetry. (2) Same electrode after dipping in the solution of 6-iodohexylferrocene in DMF followed by sonication. (3) Voltammetry of this solution at Au electrode. (4) Oxidation of the electrode prepared in (2), attesting to ferrocene immobilization in this layer. 
Figure 2

Voltammetry of haloalkylpyridines in DMF/0.1 $\mathrm{M} \mathrm{TBABF}_{4}$. Scan rate $50 \mathrm{mV} \mathrm{s}^{-1}$.

(A) 1-Bromoheptylpyridine (10 $\left.\mathrm{mmol} \mathrm{L}^{-1}\right)$ at Au electrode. (1) Multi-scan voltammetry. (2) Cathodic response after 5 cycles between $0 \mathrm{~V}$ and $-1.8 \mathrm{~V}$.

(B) 1-Chloroheptylpyridine $\left(5 \mathrm{mmol} \mathrm{L}{ }^{-1}\right)$. Multi-scan voltammetry at: (1) GC and (2) $\mathrm{Au}$ electrodes.

\section{$\underline{\text { Figure } 3}$}

(A) SEM of GC electrode with grafted Py $\left(\mathrm{CH}_{2}\right)_{8}$. (B) FTIR spectra of: (a) GC modified using $\mathrm{Py}\left(\mathrm{CH}_{2}\right)_{8} \mathrm{Br}$. (b) Same electrode after dipping in $0.1 \mathrm{M} \mathrm{HClO}_{4}$. (c) GC- $\left(\mathrm{CH}_{2}\right)_{8} \mathrm{Py}$ electrode reacted with $\mathrm{C}_{5} \mathrm{H}_{11}$ I. (d) Au electrode modified using $\mathrm{Py}\left(\mathrm{CH}_{2}\right)_{7} \mathrm{Cl}$. (e) Same electrode after contact with $0.1 \mathrm{M} \mathrm{HCl}$. (C) Nyquist and (D) Bode plots for the oxidation of Fe $(2.0 \mathrm{mmol} \mathrm{L}-$ ${ }^{1}$ ) at a $\mathrm{GC}$ electrode functionalized with $\mathrm{Py}\left(\mathrm{CH}_{2}\right)_{8}$ (preliminary reduction of $\mathrm{Py}\left(\mathrm{CH}_{2}\right)_{8} \mathrm{Br}$ ) in $\mathrm{CH}_{3} \mathrm{CN} / 0.1 \mathrm{M} \mathrm{Bu}_{4} \mathrm{NPF}_{6} . \mathrm{E}=0.31 \mathrm{~V}, \Delta \mathrm{E}=10 \mathrm{mV}$, frequency range from $134 \mathrm{kHz}$ to $52 \mathrm{mHz}$. Two time constants correspond to the charge transfer resistances $\mathrm{R}_{\mathrm{CT}}^{1}=4.7 \mathrm{kohm}$ and $\mathrm{R}_{\mathrm{CT}}^{2} \cong$ 4.97 Mohm. The inset: oxidation of Fc. (a) Freshly grafted electrode, (b) same electrode after polishing the $\mathrm{Py}\left(\mathrm{CH}_{2}\right)_{8}$ layer off. 

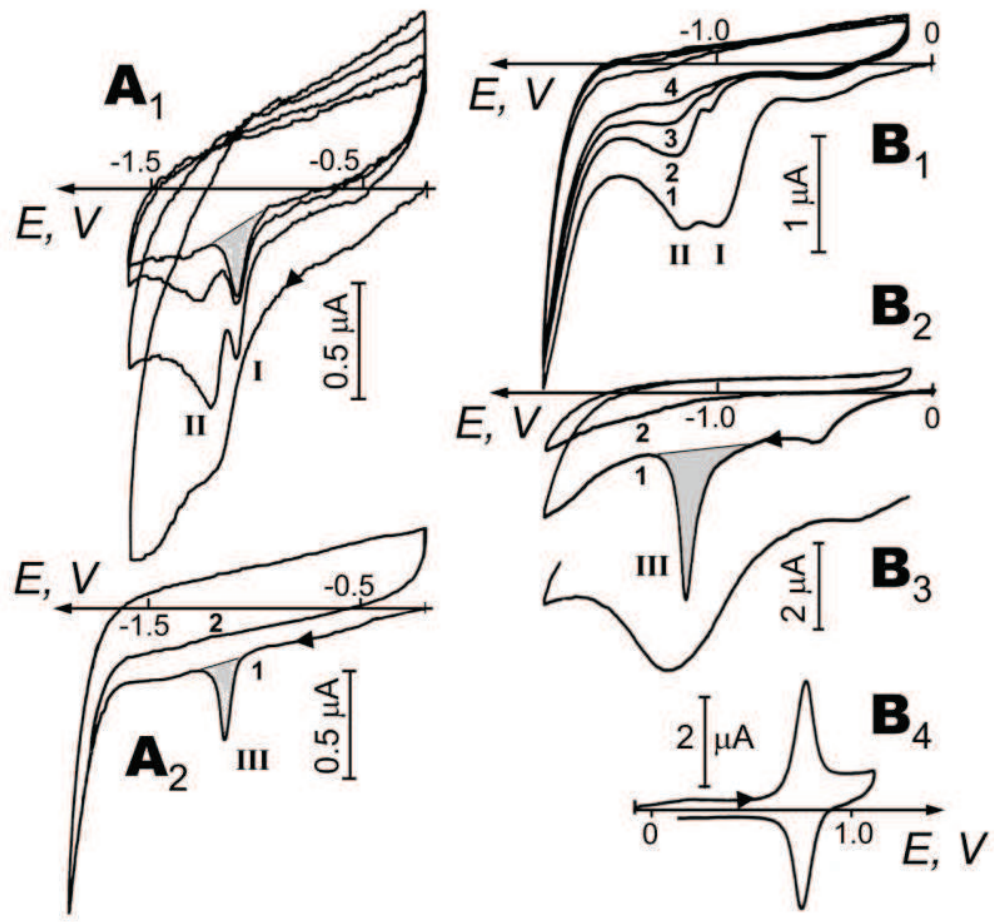

Figure 1

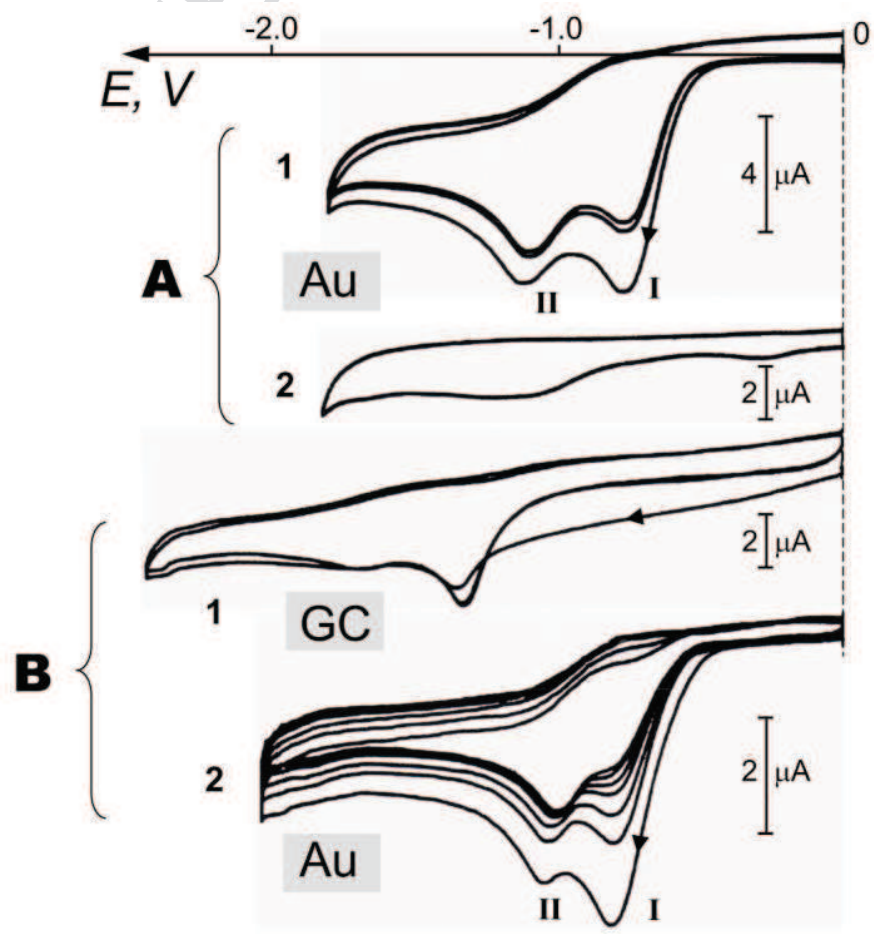

Figure 2 

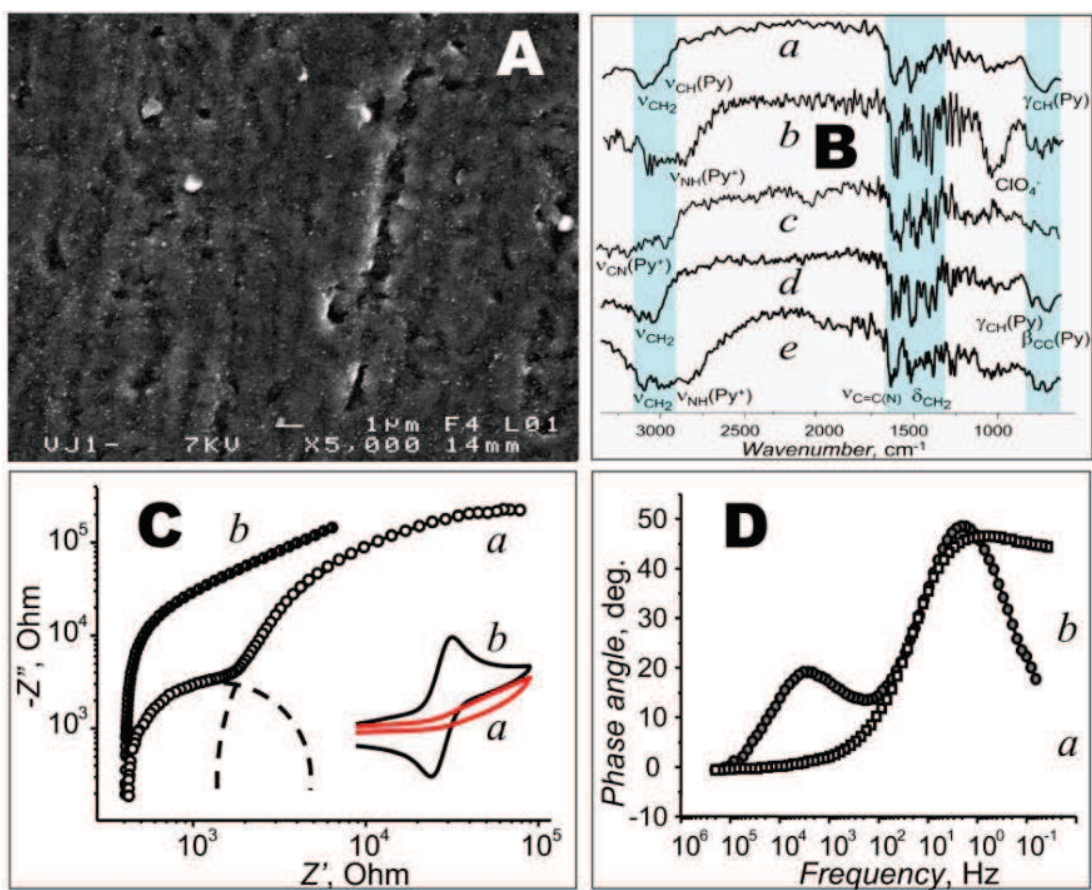

Figure 3
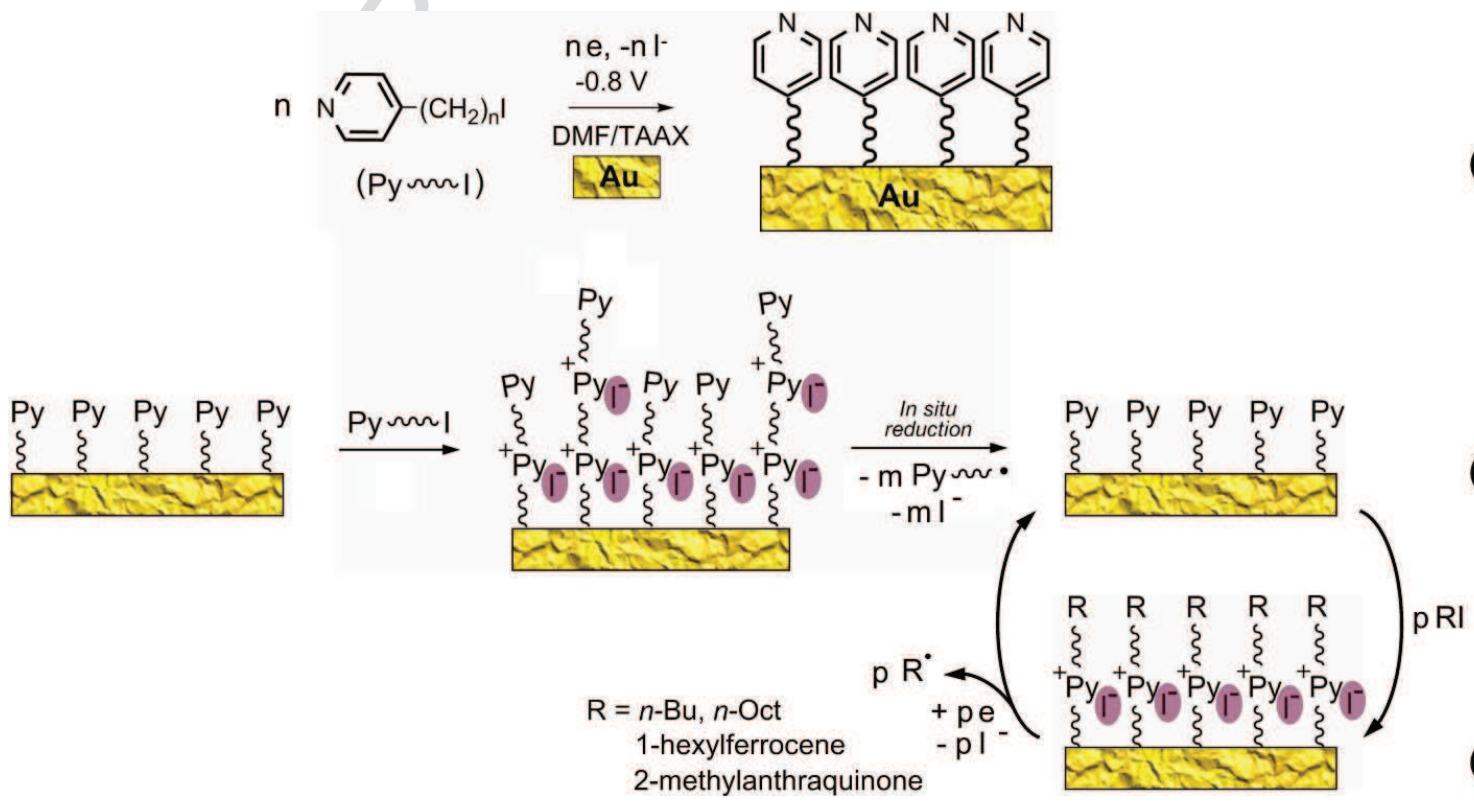

Scheme 1 

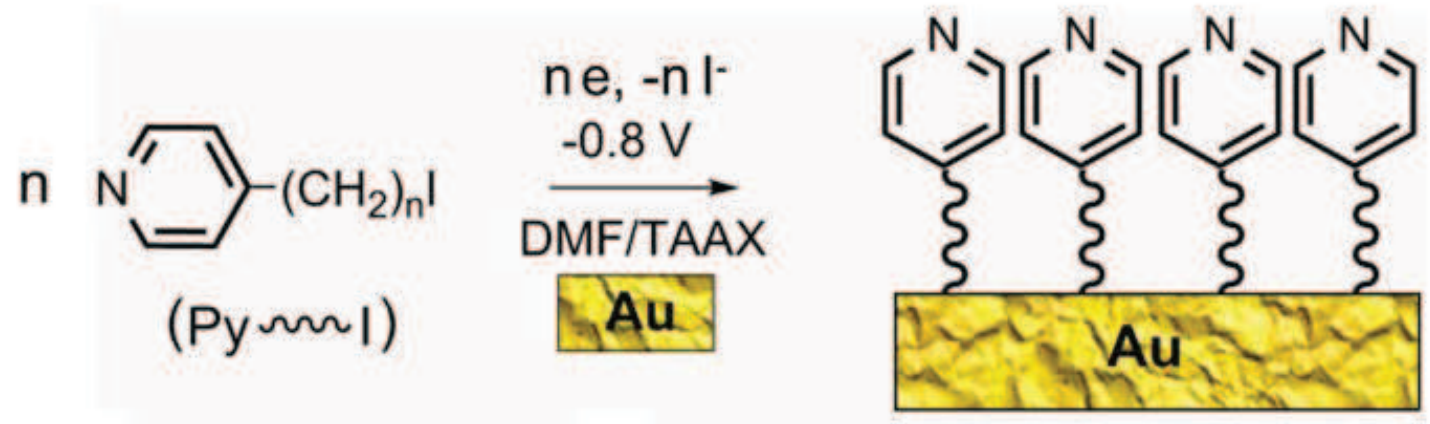

A general mode of immobilization of alkyl pyridines at gold, silver and carbon.

Graphical abstract 


\section{Highlights}

A general method for immobilizing pyridines at gold, glassy carbon, and silver is proposed > High levels of grafting are obtained $>$ Multi-strata alkyl pyridinium deposits are obtained (reaction of primary grafted pyridine with 1-iodoalkylpyridines) $>$ A simple reduction of the multi-strata composites resets the system to pyridine mono-layers $>$ The reactivity of grafted pyridine with functionalized 1-iodoalkanes permits versatile and reversible modifications of the primary pyridine layer. 